\title{
The Use of Close Relative Allo-Graft Intermingled with Auto-Graft for the Management of Extensive Burn Injury
}

\author{
ESSAM MOHAMMED MORSI, M.Sc.*; AHMED MOHAMMED BAHA-ELDIN MOSTAFA, M.D.**; \\ OMAR OSAMA SHOUMAN, M.D.**; MOHAMMED RADWAN EL-HADIDY, M.D.** and \\ SHIREEN ABDEL GHANI ABDOU MAZROA, M.D.** \\ The Burn Center, Ahmed Maher Teaching Hospital* and Faculty of Medicine, Mansoura University**
}

\begin{abstract}
Major burn injury management represents a difficult issue especially in developing countries. Skin auto-grafts is the best natural skin substitute for replacing burned skin but its rarity in major burns patients stand as an obstacle to be used. Early deep burn wounds excision and coverage of wounds more than $30 \%$ of body surface area is the main strategy for wound management in massive burns yet with the absence of skin banks (skin allo-grafts) and expensive artificial skin substitute's coverage of raw wounds by these methods is not applicable in Egypt. In this study, we try to evaluate the benefits to use both minimal sheets of auto-grafts covered by enough sheets of allo-grafts to cover all raw area after excision. Using fresh skin allo-grafts obtained from $1^{\text {st }}$ degree relative of patients as natural skin substitute. The auto-grafts are meshed 1 to 6 and fixed directly on raw areas while allo-grafts are meshed 1 to 2 and cover both auto-grafts and raw areas, noting that allo-grafts considered as temporary skin. Follow-up the clinical changing of these grafts and histopathologically analysis. Out of the 30 patients 8 had died, 10 patients needed other operations while 12 had healed with no more procedures.
\end{abstract}

Key Words: Extensive burn - Skin grafting - Allograft Autograft - Skin substitutes.

\section{INTRODUCTION}

Burn injuries are more common in less developed regions. They are among the most distressing of all injuries and a major worldwide public health catastrophe. Burns are the fourth most common type of trauma widespread [1]. Skin has a lot of important functions as controlling water and electrolytes balance, body temperature, a fence against microorganism's invasion and sensation. All are vital for survival [2]. Burn treatment represents a big challenge, especially with deep burns which has a wide surface area exceeding $30 \%$. Despite that auto-grafting is the best method for replacement of burned skin, but auto-grafting using in these cases is difficult. Modern techniques for burn management depend on early excision and cover- age. Coverage is by natural or artificial materials, in Egypt natural skin alternatives as cadaveric skin allo-grafts are not available as there are neither skin banks norxeno-grafts and artificial skin alternatives are expensive [3].

\section{Aim of study:}

The aim of this study is to detect the value of using $1^{\text {st }}$ degree relatives skin allo-grafts as an impermanent coverage intermingled with autografts permanent coveragein major burn patient after early excision of burn wound to estimate skin graft taking for both allo-graft and skin auto-graft and detecting the changes that can occur in the histology of the allo-graft skin and following-up of the quality of the grafted skin in addition to detect the morbidity and mortality of patients.

\section{PATIENTS AND METHODS}

From 2014 to 2018, 30 patients with extensive burn were admitted to Mansoura Burn Center and Ahmed Maher Teaching Hospital Burn Unit.

Patients with deep skin burn over $30 \%$ included in this study while extreme of age, presence of inhalation injury or have co-morbidity were excluded from the study.

Clinical examination and laboratory investigations were done to assess for operative fitness for both patients and donors.

Donors with blood transmitted diseases were excluded.

Within a week of burn injury, patients were admitted for the $1^{\text {st }}$ procedure for excision and grafting of as much as possible of their burn areas. 
Surgical techniques:

Allograft donor:

Using spinal anesthesia in supine position, grafts have been taken from thighs using either skin graft knife or electric dermatome. Meshing of grafts has been done with 1:2 expansion ratios.

\section{Allo and auto grafts for recipient patients:}

Under general anesthesia:

1- Small grafts were taken as auto-grafts with meshing ratio 1:6.

2- Excision of burn wound was done using graft knife till reaching bleeding surface.

3- Auto-graft sheets $1^{\text {st }}$ were applied over the raw areas then homo-graft sheets were applied after over the auto-grafts and raw area.

4- Fixation of grafts in place was done using staples.

5- Dressing of the whole area was done.

\section{Postoperative follow-up:}

3 days after operation 1 st dressing was done, and according to the condition of the wound, rate of dressings was decided.

Allo-grafts donors were discharged within 3 days and were followed-up in outpatient clinic.

Evaluation has been done by clinical examination, photos, histopathological examination of the biopsies.

Patients who suffered moderate or major changes and those who had areas not covered in the $1^{\text {st }}$ procedure were operated for a $2^{\text {nd }}$ time after 14 to 21 days to complete the coverage of the burn areas.

\section{Histological study of the skin:}

Punch biopsies were taken from the grafts including the underlying raw area at weeks ( 1 , $2,4,12$, and 24 weeks) and were examined microscopically.

\section{Tissue preparation and staining:}

Skin samples were prepared by paraffin technique. Tissue sections of 5 micrometers thickness were stained with:

- Hematoxylin and Eosin stain.

- Mallory trichrome stain.

- Periodic Acid Schiff (PAS) reaction.

Tissue sections were examined by light microscope to evaluate the structural changes in the skin. In addition, tissue sections of $4 \mathrm{um}$ thickness were stained using the immune-histochemical technique in order to investigate the expression of some biological markers associated with the skin growth and function (cytokeratins) and to evaluate the efficiency of grafts.

\section{RESULTS}

The results of study were divided into:

1- Clinical results.

2- Histopathological results.

1- Clinical results.

Patient data are summarized in Table: (1).

\section{1- Clinical results:}

During the study we could cover up to $40 \%$ of total burn surfaces area in adults and up to $100 \%$ in children by using our technique:

- All patients had done complete excision of deep burns and coverage by auto and allo grafts of $1^{\text {st }}$ degree relatives.

- Twelve patients had almost complete healing without more interventions Figs. $(1,2)$.

- 7 patients who suffered major complications (early rejection) (Fig. 3) needed to do another operation after $1{ }^{\text {st }}$ procedures, while 3 patients needed additional auto-grafting only to cover non healed areas not covered in $1^{\text {st }}$ procedure.

- 8 patients died early after the $1^{\text {st }}$ operation.

- In non-complicated cases, patients have had limited desquamation or infected areas which healed by repeated dressing. So general condition of patients ameliorated with no more loss of fluids, proteins and electrolytes. Hospital stay time decreased.

\section{2- Histopathological results:}

In non-complicated cases:

After one week of grafting, allo-graft were present covering auto-grafts and raw area (Figs. $5,6)$.

After 2 weeks, the skin adnexa had disappeared completely, Most of the epidermis of allograft appeared degenerated and desquamated, while the autograft was firmly adherent to the wound.

By 4 week, Most of the surface of wound was covered with autograft either directly by the autograftmesh itself or through epithilialization that extended from the autoepidermis. The autograft mesh had a typical skin structure with epidermis resting on a well-developed wavy basement mem- 
brane and deep rete ridges in addition to skin adnexa.

Epithelialization proceeded radially from those adnexa. The epithelialized areas were recognized by their thin epidermis and shallow or even smooth rete ridges as compared to the autograft mesh part. Epithelialization was formed of few layers of cells that continued to cover non epithelized distal areas of wound and dermal elements of allograft Fig. (7).
By week 12, the wound surface was almost completely covered with epidermis. The different tissue layers of the skin and skin adnexa were clearly visible (Fig. 8).

On the other hand, biopsies obtained from patients complicated with aggressive graft rejection showed either necrosis of large parts of the grafts or even complete dissolution and separation of the grafts from underlying wound tissue (Figs. 10,11).

Table (1): Patients data.

\begin{tabular}{|c|c|c|c|c|c|c|c|c|c|c|}
\hline No & Age & Sex & Etiology & $\begin{array}{l}\% \text { of burn of } \\
\text { (TBSA) }\end{array}$ & Donor & $\begin{array}{l}\text { Time of } \\
1^{\text {st }} \text { sur. }\end{array}$ & $\begin{array}{l}\% \text { of area cover } \\
\text { after excision }\end{array}$ & $\begin{array}{l}\text { Complication } \\
\& \text { mortality }\end{array}$ & $2^{\text {nd }}$ sur. & $\begin{array}{c}\text { Hospital } \\
\text { stay }\end{array}$ \\
\hline 1 & 3 yrs & $\mathrm{F}$ & Scald & $50 \%$ & Mother & $4^{\text {th }}$ day & $100 \%$ & - & - & 14 days \\
\hline 2 & $58 \mathrm{yrs}$ & M & Flame & $60 \%$ & Son & $5^{\text {th }}$ day & $60 \%$ & Death & & 10 days \\
\hline 3 & 4 yrs & $\mathrm{F}$ & Scald & $40 \%$ & Mother & $5^{\text {th }}$ day & $100 \%$ & - & - & 15 days \\
\hline 4 & $10 \mathrm{yrs}$ & $\mathrm{F}$ & Scald & $40 \%$ & Father & $6^{\text {th }}$ day & $100 \%$ & Localized infection & & 25 days \\
\hline 5 & $40 \mathrm{yrs}$ & $\mathrm{F}$ & Flame & $75 \%$ & Brother & $6^{\text {th }}$ day & $50 \%$ & & $\begin{array}{l}3 \text { weeks } \\
\quad \text { (auto-graft only) }\end{array}$ & 50 days \\
\hline 6 & 32 yrs & M & Flame & $60 \%$ & Brother & $5^{\text {th }}$ day & $70 \%$ & Partial loss of grafts & 3 weeks & 57 days \\
\hline 7 & 7 yrs & M & Flame & $40 \%$ & Gmother & $5^{\text {th }}$ day & $100 \%$ & - & - & 17 days \\
\hline 8 & $15 \mathrm{yrs}$ & M & Flame & $45 \%$ & Father & $6^{\text {th }}$ day & $100 \%$ & & & 16 days \\
\hline 9 & $5 \mathrm{yrs}$ & M & Scald & $40 \%$ & Mother & $7^{\text {th }}$ day & $100 \%$ & & & 21 days \\
\hline 10 & $38 \mathrm{yrs}$ & M & Flame & $60 \%$ & Brother & $6^{\text {th }}$ day & $70 \%$ & Death & & 7 days \\
\hline 11 & $34 \mathrm{yrs}$ & $\mathrm{F}$ & Scald & $50 \%$ & Mother & $6^{\text {th }}$ day & $90 \%$ & Death & & 10 days \\
\hline 12 & $51 \mathrm{yrs}$ & $\mathrm{F}$ & Scald & $70 \%$ & Brother & $5^{\text {th }}$ day & $50 \%$ & & $\begin{array}{l}3 \text { weeks } \\
\quad \text { (auto-gratf only) }\end{array}$ & 38 days \\
\hline 13 & $48 \mathrm{yrs}$ & $\mathrm{F}$ & Flame & $65 \%$ & Son & $7^{\text {th }}$ day & $70 \%$ & $\begin{array}{l}\text { Infection with graft } \\
\text { partial loss }\end{array}$ & 4 weeks & 61 days \\
\hline 14 & 44 yrs & M & Flame & $70 \%$ & Brother & $5^{\text {th }}$ day & $60 \%$ & $\begin{array}{l}\text { Infection with graft } \\
\text { partial loss }\end{array}$ & 5 weeks & 65 days \\
\hline 15 & $30 \mathrm{yrs}$ & M & Flame & $60 \%$ & Father & $4^{\text {th }}$ day & $50 \%$ & - & $\begin{array}{l}3 \text { weeks } \\
\quad \text { (auto-gratf only) }\end{array}$ & 52 days \\
\hline 16 & 34 yrs & M & Flame & $40 \%$ & Brother & $5^{\text {th }}$ day & $100 \%$ & & & 18 days \\
\hline 17 & $2 \mathrm{yrs}$ & M & Scald & $70 \%$ & Mother & $4^{\text {th }}$ day & $60 \%$ & Death & & 9 days \\
\hline 18 & $50 \mathrm{yrs}$ & $\mathrm{F}$ & Flame & $75 \%$ & Sister & $5^{\text {th }}$ day & $50 \%$ & Death & & 8 days \\
\hline 19 & $20 \mathrm{yrs}$ & M & Flame & $60 \%$ & Father & $7^{\text {th }}$ day & $70 \%$ & $\begin{array}{l}\text { Infection with graft } \\
\text { partial loss }\end{array}$ & 3 weeks & 45 days \\
\hline 20 & 9 yrs & M & Flame & $30 \%$ & Grandmother & $6^{\text {th }}$ day & $100 \%$ & & & 19 days \\
\hline 21 & $25 \mathrm{yrs}$ & $\mathrm{F}$ & Scald & $70 \%$ & Mother & $6^{\text {th }}$ day & $50 \%$ & $\begin{array}{l}\text { Infection with graft } \\
\text { partial loss }\end{array}$ & 3 weeks & 45 days \\
\hline 22 & $48 \mathrm{yrs}$ & $\mathrm{F}$ & Scald & $80 \%$ & Son & $6^{\text {th }}$ day & $60 \%$ & Death & & 11 days \\
\hline 23 & $5 \mathrm{yrs}$ & M & Scald & $40 \%$ & Father & $4^{\text {th }}$ day & $100 \%$ & Death & & 6 days \\
\hline 24 & $26 \mathrm{yrs}$ & $\mathrm{F}$ & Scald & $75 \%$ & Mother & $6^{\text {th }}$ day & $60 \%$ & $\begin{array}{l}\text { Infection with graft } \\
\text { partial loss }\end{array}$ & 4 weeks & 59 days \\
\hline 25 & $30 \mathrm{yrs}$ & $\mathrm{F}$ & Flame & $65 \%$ & Husband & $6^{\text {th }}$ day & $60 \%$ & Death & & 7 days \\
\hline 26 & $4 \mathrm{yrs}$ & M & Scald & $50 \%$ & Mother & $5^{\text {th }}$ day & $100 \%$ & & & 17 days \\
\hline 27 & $7 \mathrm{yrs}$ & M & Scald & $40 \%$ & Father & $5^{\text {th }}$ day & $100 \%$ & $\begin{array}{l}\text { Infection with graft } \\
\text { partial loss }\end{array}$ & 5 weeks & 66 days \\
\hline 28 & $44 \mathrm{yrs}$ & M & Flame & $50 \%$ & Brother & $4^{\text {th }}$ day & $100 \%$ & & & 18 days \\
\hline 29 & $14 \mathrm{yrs}$ & M & Flame & $40 \%$ & Father & $6^{\text {th }}$ day & $100 \%$ & & & 20 days \\
\hline 30 & 6 yrs & $\mathrm{F}$ & Scald & $40 \%$ & Mother & $5^{\text {th }}$ day & $100 \%$ & & & 22 days \\
\hline
\end{tabular}



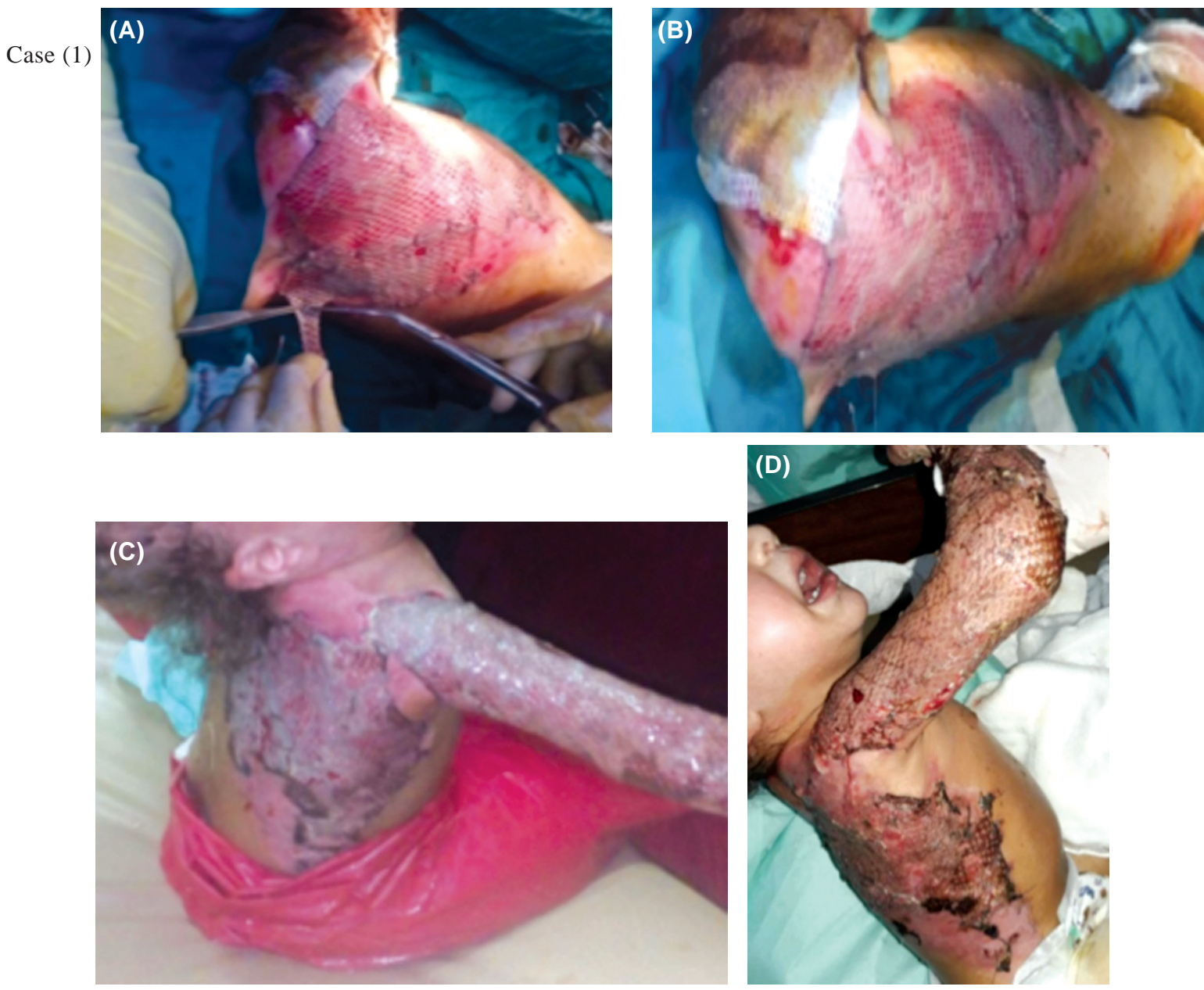

Fig. (1): Case (1) (A and B) Intraoperative photos showing allo and auto grafts of a baby with burn affecting the back and right arm, (C) Early postoperative view during the $1^{\text {st }}$ dressing, (D) Grafts 2 weeks postoperative.

Case (2)
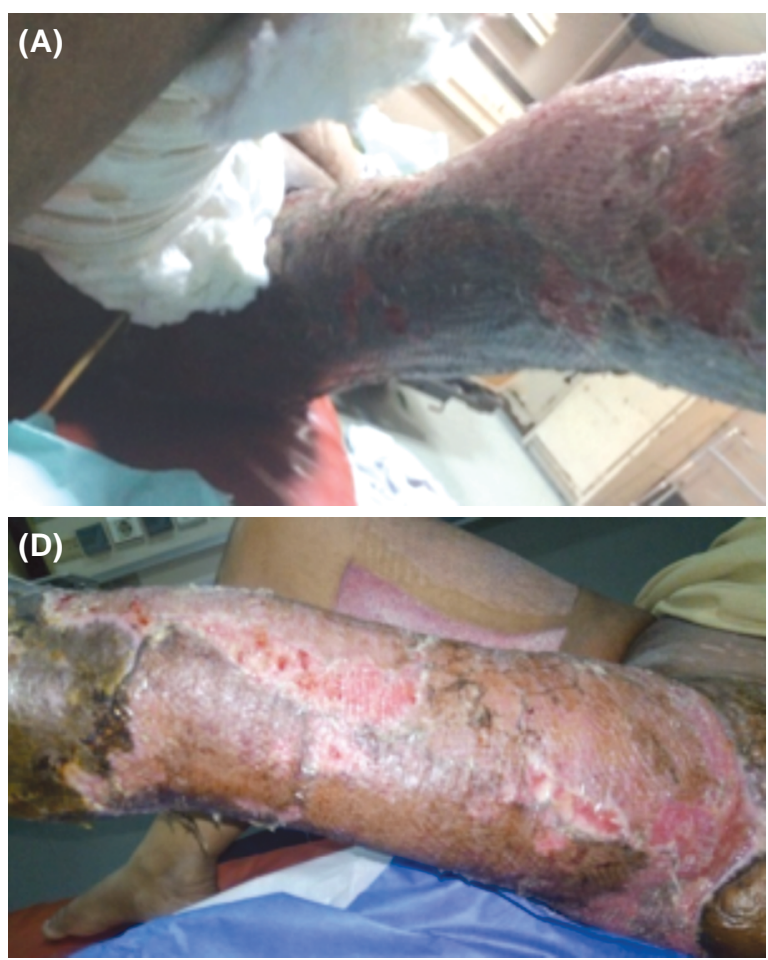
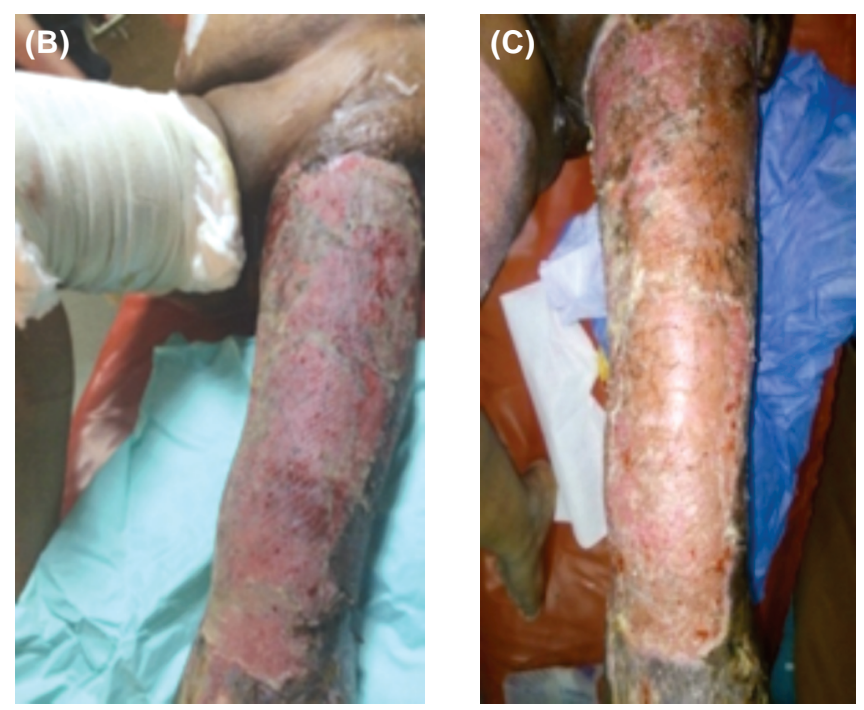

Fig. (2): Case (2) (A) Shows a female patient with burn affecting the left lower limb, (B and C) Early postoperative views showing the grafts during $1^{\text {st }}$ dressing, (D) Anterior and lateral views of the grafts after 2 weeks of operation with little desquamation of allograft with healed donor areas over the right thigh. 
Case (3)
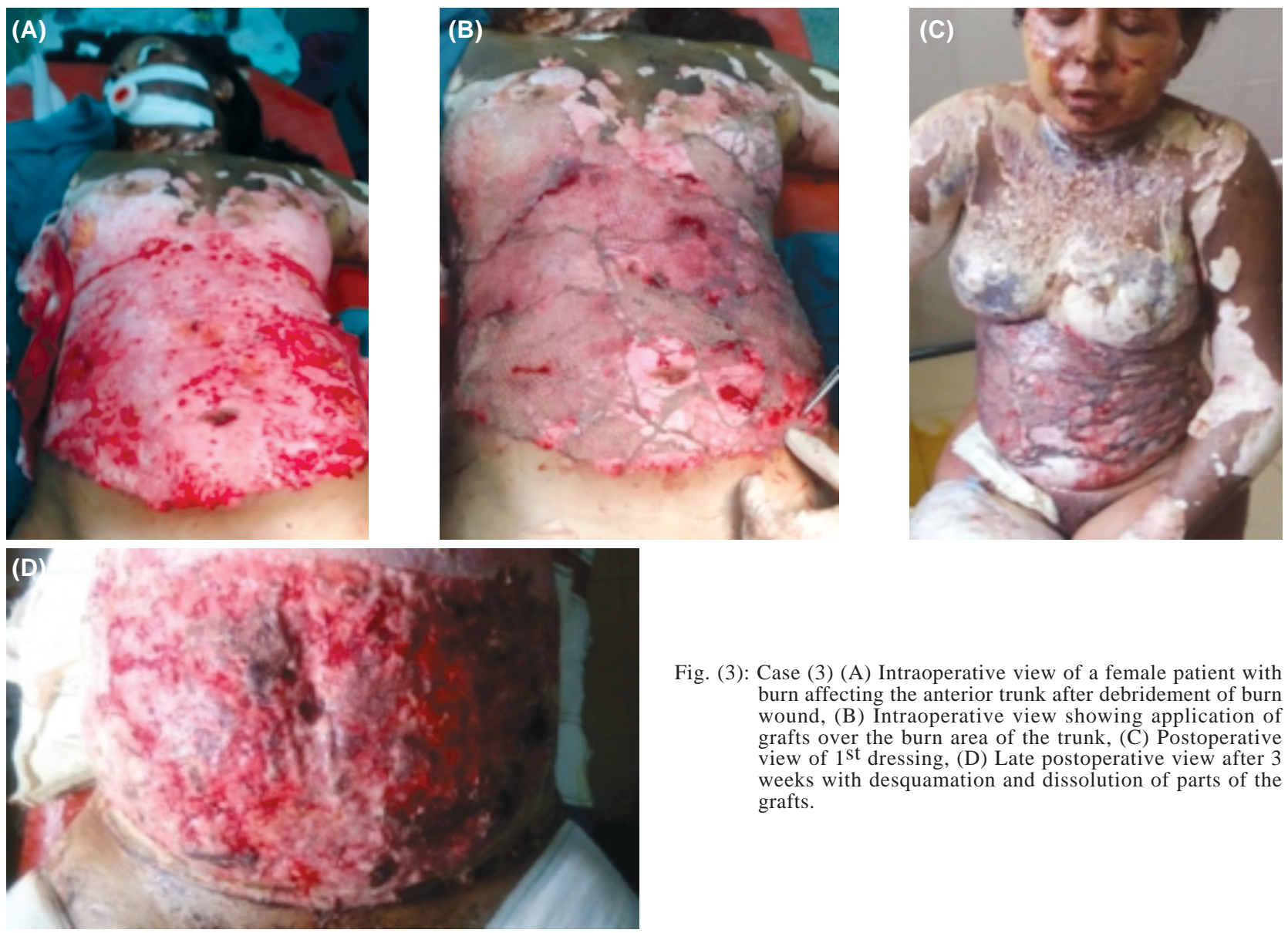

Fig. (3): Case (3) (A) Intraoperative view of a female patient with burn affecting the anterior trunk after debridement of burn wound, (B) Intraoperative view showing application of grafts over the burn area of the trunk, (C) Postoperative view of $1^{\text {st }}$ dressing, (D) Late postoperative view after 3 weeks with desquamation and dissolution of parts of the grafts.

2- Results of Histopathology

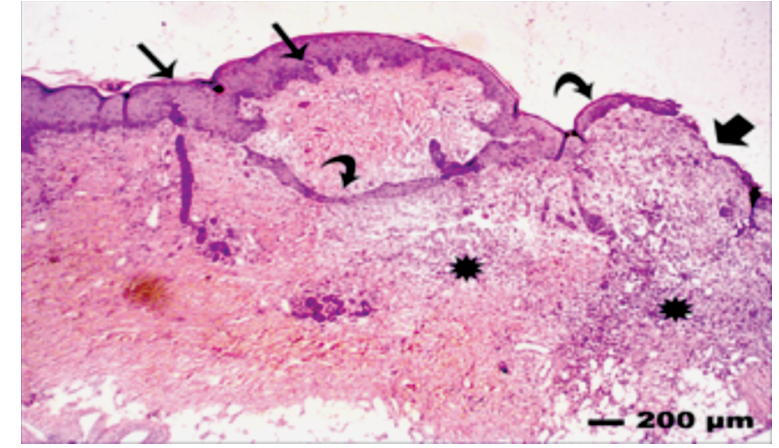

Fig. (4): A photomicrograph of tissue biopsy obtained one week after grafting showing a superficial layer of allograft (straight thin arrows), then the autograft (curved arrows) and underneath wound tissue containing inflammatory cells infiltration (stars). Note the area of the wound not covered with graft (thick arrow). (H\&E X40).

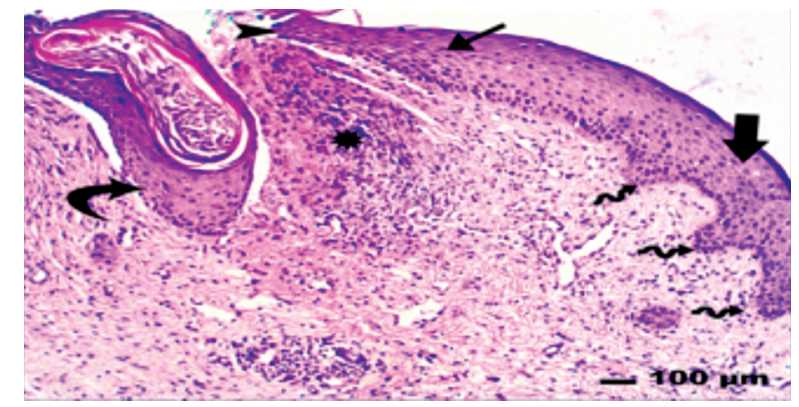

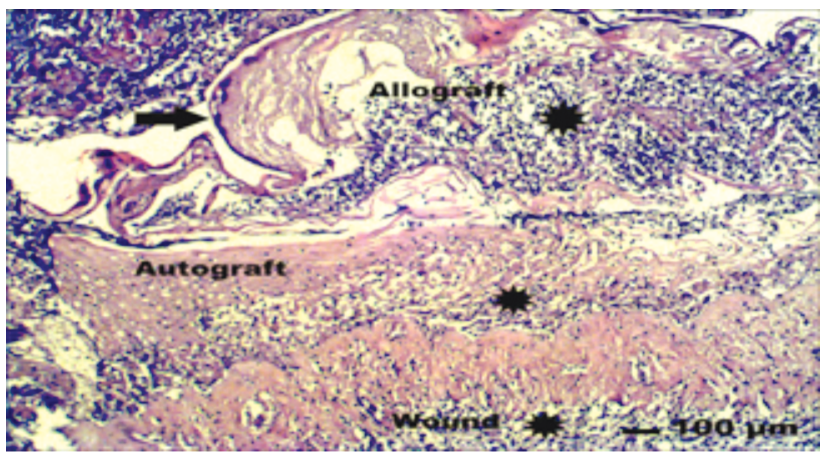

Fig. (5): A photomicrograph of tissue biopsy obtained 2 weeks after grafting showing a superficial allograft with degenerated epidermis (thick arrow), and a layer of autograft firmly adherent to the surface of the wound. Note the intense infiltration with inflammatory cells (stars) to the 3 tissue layers, and the absence of skin adnexa. (H\&E X100).

Fig. (6): A photomicrograph of tissue biopsy obtained 4 weeks after grafting showing the covering of the wound surface with the autograft mesh (Thick arrow) or through the extension of the auto-epidermis to form epithelialization (arrow). Note the integration of the dermal elements of allograft (star) with the dermal component of the skin after being covered with the newly formed epithelium (arrow head). Allodermis is heavily infiltrated with inflammatory cells. The autograft mesh had a typical skin structure with deep rete ridges (Zigzag arrows) in addition to intact adnexa as hair follicle (curved arrow). (H\&E X100). 


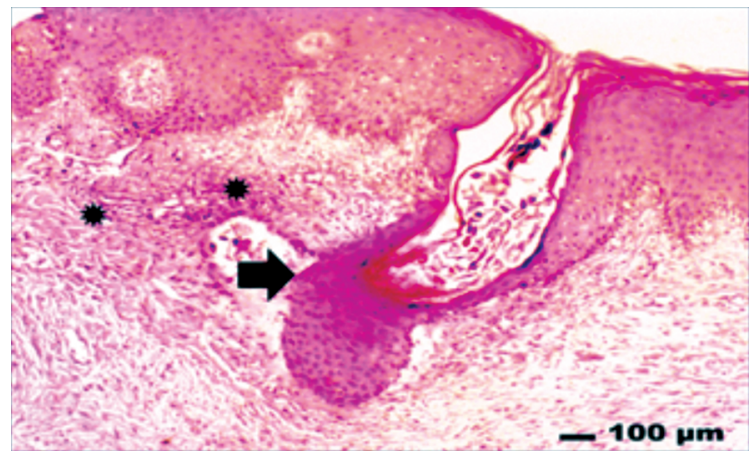

Fig. (7): A photomicrograph of tissue biopsy obtained 12 weeks after grafting showing an area of allodermis (stars) in the skin dermis adjacent to a hair follicle (thick arrow). (H\&E X100).

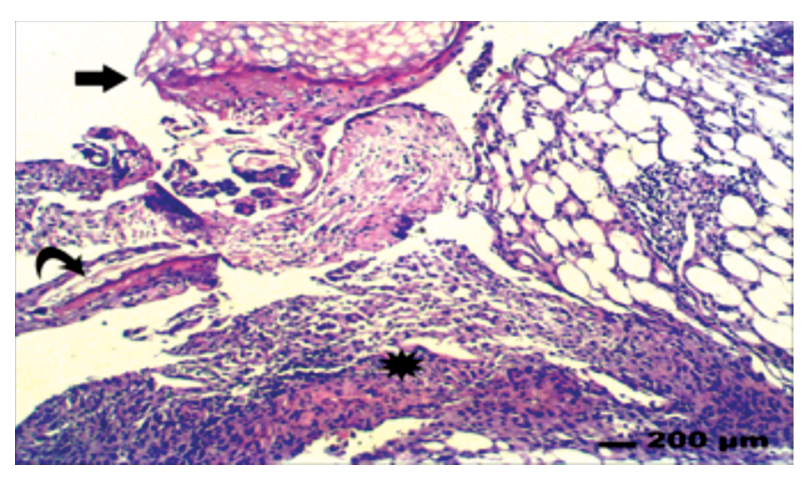

Fig. (9): A photomicrograph of tissue biopsy obtained one week after grafting showing the aggressive graft rejection with necrosis and separation of allograft (thick arrow) and autograft (curved arrow) from wound (star). (H\&E X40).

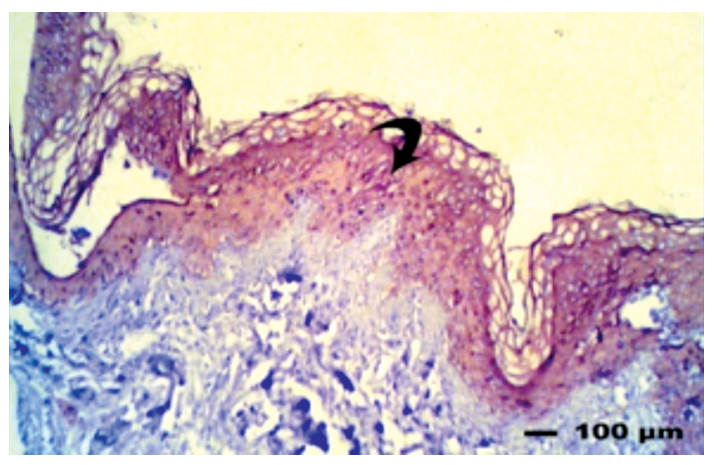

Fig. (11): A photomicrograph of tissue biopsy obtained two weeks after grafting showing strong reaction in autograft (curved arrow). (Pan cytokeratin IHC X100).

\section{DISCUSSION}

Extensive burn can be a cause of fatality in patients especially if not treated wisely and as fast as possible in order to cover the resulting raw areas that put a burden on the body system as they represent an entranceto micro-organisms of different types and a way to lose body fluids and different components of the body. Patients with extensive burns may have no available skin to be used to cover such large areas of skin loss. Many trials to

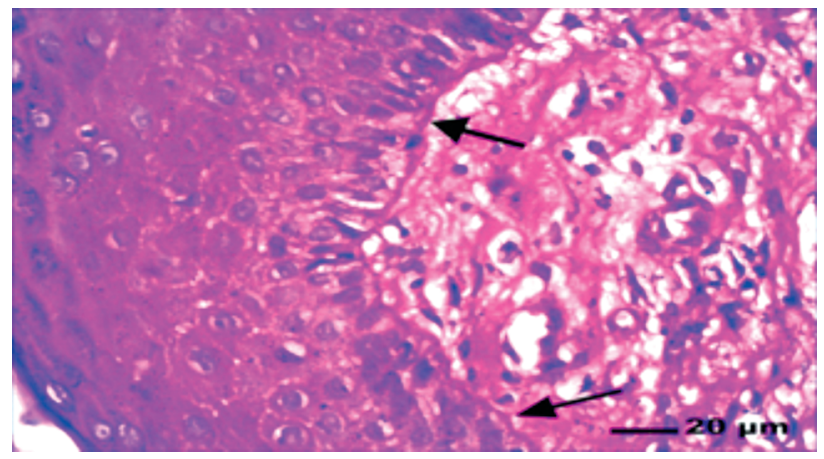

Fig. (8): A photomicrograph of tissue biopsy obtained 24 weeks after grafting showing well developed wavy basement membrane (arrows) under the epithelium of the epidermis. (PAS-X400).

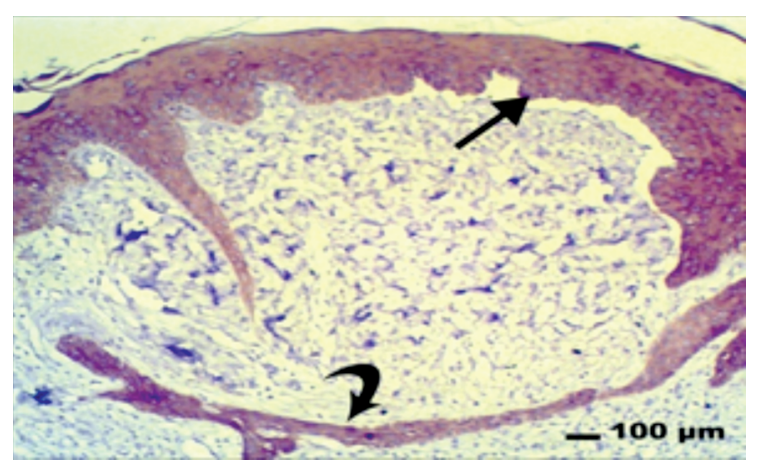

Fig. (10): A photomicrograph of tissue biopsy obtained one week after grafting showing strong reaction in allograft (arrow) and in autograft (curved arrow). (Pan cytokeratin IHC $\mathrm{X} 100)$.

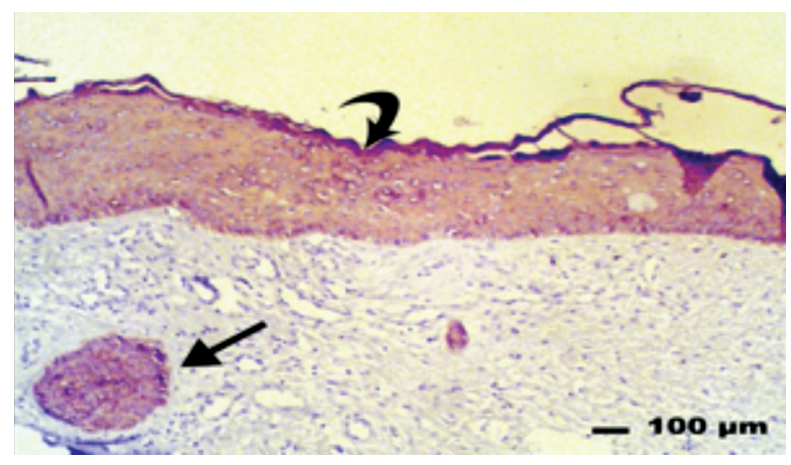

Fig. (12): A photomicrograph of tissue biopsy obtained 4 weeks after grafting showing strong reaction (curved arrow) inthe newly formed epidermis with shallow rete ridges covering the wound and in the newly formed hair follicles (arrow). (Pancytokeratin IHC X100).

overcome this obstacle had been taken over in the last decades.

Different materials were used with different techniques to help covering large areas of skin loss in shorter time. These skin substitutes reduce bacterial count, minimize loss of water, protein, and electrolytes, restore function, facilitate early motion, and provide coverage of important structures. 
Skin substitutes of biological and synthetic origin have been tried throughout last decades; biological like xenografts, amniotic membrane and allografts and Synthetic as biobrane, dermagraft and integra.

Also tissue engineering appeared to help in burn care and provided skin substitutes like cultured keratinocytes.

On the other hand, Donor skin may be prepared for use in numerous ways (treated with glycerol and frozen with liquid nitrogen, or dried with lyophilization and freezing) [4].

Live donor skin doesn't require any complicated preparation or preservation. It can be used immediately after harvesting and constitutes a ready source of skin substitute. We agree with Suthanthiran, in 1997, who stated that the closer the donor is to the patient, the less likely it is to be rejected [5].

Allo-grafts are considered one of the respectful skin substitutes in absence of autologous skin, and also in absence of facilities such as skin banking and keratinocytes culturing. These facilities are not available in most of developing countries because they need sophisticated technologies and expensive equipment and instrumentation.

In our study thirty patients between 2014-2018 with extensive burns of (30\%-50\%) deep $2^{\text {nd }}$ degree and $3^{\text {rd }}$ degree burn underwent operations of total excision of burn tissue during $1^{\text {st }}$ week of injury and coverage by combined intermingled auto-grafts meshed up to (1-6) expansion ratio and allo-grafts meshed up to (1-2) expansion ratio of $1^{\text {st }}$ degree relative of the recipient.

Pre-operative examination and investigation were done to patients and donors for fitness to surgery; virology was done for donors for to exclude HIV, HBV and HCV.

From the thirty patients who underwent excision and coverage by auto and allo-grafting: 8 patients were died post, 12 patients did not need second operation while 7 patients needed $2^{\text {nd }}$ operation by auto and allo grafting and 3 patients needed $2^{\text {nd }}$ operation by auto-grafts.

Post operatively patients were admitted to the intensive care unit for follow-up from 2 days up to 5 days then send to the ward when their general conditions were stable. $1^{\text {st }}$ dressing was done on the $3^{\text {rd }}$ day, pictures were taken and $1^{\text {st }}$ biopsy was done on the end of 1 st week.

We agree with Converse and Duchet, in 1947, Coenen, et al., in 1990, and Leodoro, et al., in 2014, who stated that abundance of donors of live skin allografts, and minimal preoperative preparation time is ideal for developing and poor countries with no available expensive facilities like skin banking $[6,7,8]$.

In our study, we used the intermingled combined allografts and autografts to cover these large areas of skin loss in the shortest possible time. We applied the same ratios of meshing of allografts and auto grafts as those of $[\mathbf{9 , 1 0 ]}$.

During our study we could cover up to $40 \%$ TBSA in adults and $60 \%$ TBSA in children using that technique. This conforms with the results of Calota, et al., in 2012, who reported that Patients with extensive burns (TBSA over $45 \%$ ) can benefit from treatment with split thickness skin allotransplants [10].

During our study, 10 out of 22 patients (45.45\%) needed further operation, this is comparable to the study done by Phipps and Clarke, in 1991, who studied the use of intermingled allografts and autografts in treatment of 10 children with extensive burn, and reported that 5 patients out of 10 patients $(50 \%)$ needed further operations using either autografts only or another session of intermingled allografts and auto-grafts [11].

Also, our study is comparable to the study of El-Meanawy, et al., in 2019, who found that among those treated with combined technique 5 out of 24 patients $(20.83 \%)$ needed another session, while in our study 7 out of 22 patients $(31.82 \%)$ treated with the same technique needed another session [12].

\section{Rejection:}

Epidermal layer of allograft is containing Langerhans cells that express class II antigens on their surface which are responsible for the inevitable immune rejection.

But vascularized allogeneic skin grafts typically remain intact on the wound of a burn patient for 2 to 3 weeks (Figs. 4,5,6), that is because the immunity of these patients are severely compromised so the immune reaction and rejection are late, then with improvement of the patient general condition the allograft start to reject gradually (Figs. 4,5,6). During these 2 to 3 weeks epithelium 
cells of autogrfts are spreading to cover raw areas, this is almost takes 4 weeks (Fig. 7).

In our study, we did not use local (glucocorticoidsor systemic immunosuppressant drugs as cyclosporine.

Studying the allografts microscopically we found thatthe ectodermal and endodermal components of the allograft, i.e. epidermis, endothelium, and skin adnexa, are rejected over a period of the 1 st 3 weeks (Figs. 4,5,6,7), in all the allografts. This matches with the studies of Phipps and Clarke, in 1991, and Qaryoute, et al., in 2001, who stated that it takes about 15-25 days. Yet, Alexander et al., in 1981, reported that it may start even earlier by the $3^{\text {rd }}$ day and may reach late up to the $30^{\text {th }}$ day $[1,11,13]$.

Survival of allo-grafts occurred from 1 to 3 weeks may be due to the immunosuppressant effect of thermal injury on patient's immunity this mach with the study of Ninnemann et al., 1979 with reports of allograft skin survival for up to 67 days, due in part to the inherent immunosuppression of extensive burn injury [15].

We agree with Phipps and Clarke, in 1991, and Qaryoute, et al., in 2001, and Alexander, et al., in 1981, that the dermis of the allografts is the component contributing as a scaffold for autografts and share in healing rather than the epidermis.

Also microscopic studies revealed that epithelial outgrowth from the autografts was faster than from the allografts, but both types of grafts show good took and were well vascularized. This is consistent with the study done by Alexander, et al., in 1981, who reported an average of $99 \%$ autograft take and $95 \%$ allograft take, and that the rejection of the allografts was not associated with acute inflammation or loss of autografts [9].

Regarding the mortality rate, we found that during our study 8 patients died out of 30 patients included in the study in a rate of $26.67 \%$. Comparing this rate with other studies, we found that the rate differs from a study to another.

In the studies done by (Phipps and Clarke, in 1991, Coruh, et al., 2005, and El-Meanawy, et al., in 2019), the mortality rates were $10 \%$ (one patient out of 10 patients), $58.82 \%$ (10 patients out of 17 patients), and $11 \%$ (6 patients out of 54 patients) respectively $[\mathbf{1 1}, \mathbf{1 2}, 16]$.

We believe that the mortality rates differ due to multiple factors including Number of patients included in the study, selection of patients (regarding percentage of total body surface area of deep burn, general condition of the patient, presence of any co morbidity with or without presence of inhalation injury).

Also, we believe that to study the relation between our way of management and mortality rate, a mass analytical study on a huge number of patients must be done.

Throughout the study, the hospital stay of our patients was ranging from 50- 80 days. This agree with the studies done by Calota, et al., in 2012, as their patients stay in hospital for about 60-80 days. Yet, the study done by Chua, et al., in 2018, discussed that the hospital stay of their patients reached up to more than 100 days $[\mathbf{1 0 , 1 4 ]}$.

\section{Conclusion:}

Major burn management represents a challenge to plastic surgeons, excision and coverage of wounds is the best method for treatment. Autografting is the gold stander for coverage but unavailable donor sites in major burn patients made surgeons search for skin alternatives for coverage. In our study we use $1^{\text {st }}$ degree relative as allografts, its completely viable, sterile (no processing or storage) and cheap.

Allograft plays its role of wounds coverage till epithelization of wounds completed by autografts. We think that it is a reliable method for major burn management.

\section{REFERENCES}

1- Tompkins R.G.: Survival from burns in the new millennium: 70 years experience from a single institution. Ann. Surg., 261 (2): 263-8: 2015.

2- Chu D.H.: Overview of biology, development, and structure of skin. In K. Wolff, L.A. Goldsmith, S.I. Katz, B.A. Gilchrest, A.S., 241-242, 2008.

3- Daugherty M.D., Timothy H.F. M.D., Amanda Ross M.D. and Michael Neumeister M.D.: Surgical Excision of Burn Wounds Best Practices Using Evidence-Based Medicine. Clin. Plastic Surg., 33-38, 2017.

4- Saidi S.: Live Skin Allograft in The Treatment of Severe Burn. Annals of African Surgery, 13 (2): 77-80, 2016.

5- Sutithanthiran N.: Acute rejection of renal allografts: Mechanistic insights and therapeutic options Kidney International, 51: 1289-1304, 1997.

6- Converse J.M. and Duchet G.: Successful homologous skin grafting in a war burn using an identical twin as a donor. Plastic and Reconstructive Surgery, 3: 342, 1947.

7- Coenen J.M.H., Klasen H.J. and Sauer F.W.: Successful homografting in an elderly patient with extensive burns using his identical twin brother as skin donor. Burns, 16 (3): 225-226, 1990. 
8- Leodoro B., Chang A. and Cama J.K.: Live sibling skin allo-grafts for severe burns in a pediatric patient. Journal of Pediatric Surgery Case Reports, 2 (11): 498-500, 2014.

9- Alexander J.W., MacMiian B.W., Law E. and Kittur D.S.: Treatment of severe bums with widely meshed skin autograft and meshed skin allograft overlay. Journal of Trauma, 21: 433, 1981.

10- Calota D.R., Nitescu C., Florescu I.P., et al.: Surgical management of extensive burns treatment using allografts. J. Med. Life, 5 (4): 486-490, 2012.

11- Phipps and Clarke J.A.: The use of intermingled autograft and allograft skin in the treatment of major burns in children. Br. J. Plastic Surgery, 44 (8): 608-611, 1991.

12- El-Meanawy Amr Mahmoud, Tarek Fouad Keshk, Magdy Ahmed Lolouah and Medhat Samy Hassan: The reliability of use of combined homograft and autograft in management of major burns, 6 (5): 1446-1452, 2019.

13- Qaryoute S., Mirdad I. and Hamail A.A.: Usage of autograft and allograft skin in treatment of burns in children. Burns, 27: 599-602, 2001

14- Chua A.W.C., Khoo Y.C., Truong T.T.H., Woo E., Tan B.K. and Chong S.J.: From skin allograft coverage to allograftmicrograft sandwich method, 44 (5): 1302-1307, 2018.

15- Ninnemann J.L., Fisher J.C. and Frank H.A.: Prolonged Survival of Human Skin Allografts Following Thermal Injury Transplantation, 25 (2): 69-72, 1979.

16- Coruh Atilla M.D., Zeynep Tosun M.D. and Umut Ozbebit M.D.: Close Relative Intermingled Skin Allograft and Autograft Use in the Treatment of Major Burns in Adults and Children Journal of Burn Care \& Research, 26 (6): 471-477, 2005. 